\title{
The distribution of urban public services: the case of parks and recreational services in Ankara
}

\author{
Feyzan (Beler) Erkip \\ Department of Interior Architecture and Environmental Design, Faculty of Art, Design and Architecture \\ Bilkent University, 06533 Bilkent, Ankara, Turkey
}

\begin{abstract}
The provision of urban services is a central issue in urban planning and development. The distribution of these services to guarantee their effective utilization is another focus of concern. As citizens are heterogeneous in character, their access to urban public services is affected by the distribution of those services. Access to some services with fixed facilities is limited by the location of the service within a city. In this study, which focuses on the city of Ankara, Turkey, the parks and recreational facilities are evaluated in terms of both service and user characteristics. Since the service has a merited reputation due to the public and its free provision, a local government aiming for a just distribution claims to distribute the service 'equally' on a geographical basis. This study evaluates the current policy and proposes distributional justice to achieve a truly equitable distribution, which is sensitive to the characteristics of different citizen groups, instead of the territorial justice (i.e. park distribution based on geography) that cannot satisfy the conditions of effective utilization. (c) 1997 Elsevier Science Ltd. All rights reserved
\end{abstract}

Keywords: urban studies, distributional justice, parks and recreation

\section{Introduction}

The practical importance of service distribution in urban areas is based on the need for services (such as police and fire protection, water supply, sanitation and waste disposal and transportation) for the viability of urban life. Other public services-paved streets, street lights, parks and recreational facilities, and libraries - contribute to the comfort level and wealth of the citizens (Lineberry and Welch, 1974).

In an urban environment, especially in the metropolis, spatial constraints are extremely important when dealing with service distribution. For most of the fixed urban services such as parks, libraries and public health facilities, physical proximity is required. Pinch (1985) suggests that such 'point-specific' services create a tapering effect because of travel costs together with time and effort, all of which tend to increase with distance. In any case, the spatial distribution of services affects the distribution of wealth among citizens. As Lineberry (1977) states, "urban politics is essentially a politics of spatial allocation of advan- tages and disadvantages", where he defines public service decisions as "fundamentally redistributive mechanisms" or "hidden multipliers of income." Toulmin (1988) specifies the ideal goal of city government as providing services to maintain the viability of each neighbourhood. This leads to the question of what kind of service distribution could improve the conditions of disadvantaged neighbourhoods. However, there is a wide consensus over the welfare analysis, viz, that it offers relatively little information on what the 'desirable distribution' is, and cannot give criteria for 'distributional justice' (Walker, 1981; Bourassa, 1992). ${ }^{1}$ The normative character of the answers to

\footnotetext{
'The distribution problem is even more important when considering the current state of the welfare debate in urban politics. The city is increasingly perceived as a private space, in which a good deal of exclusion from any service area (including parks and recreation) occurs. Recent trends indicate possible radical changes in the role of local governments in city politics, which are expected to affect the structure of urban service provision (see Mayer, 1994). These issues deserve further attention with a broader perspective, and are not considered in detail in the content of this study.
} 
such questions seems to be inevitable. The objectives of society, that are set with respect to political, social and ethical considerations, determine the resultant decisions on distribution (Walker, 1981). This being the case, the nature of the distribution of urban public services can only be understood by first determining the conditions of a particular society.

This study aims to approach the problem of distribution of urban public services by means of an empirical survey on parks and recreational services in Ankara. The theoretical background, which is given in the next section, is followed by the specific characteristics of parks and recreational services and their supply conditions in Ankara metropolitan city. Analyses and results of the empirical survey are then presented, with a related discussion on policy implications and concluding remarks at the end of the paper.

\section{Determining factors in the distribution of urban public services}

Urban public services are traditionally covered under the definition of public goods that are consumed by many citizen-consumers simultaneously; exclusion from their benefits is impossible or very difficult. However, there is a long-lasting debate over this definition, especially the condition of non-exclusion, as public goods characteristics have the following distribution problems.

(1) The problem of equal versus selective access. It is claimed that equal access is a normative concept and that there are no inherently public goods or services. A natural consequence is that exclusion is possible from all goods and services as far as exclusion from the group receiving the services is possible (Goldin, 1977). This paper will show the role of distributional patterns on access levels for different user groups.

(2) The problem of free rides. Individuals tend to misrepresent their preferences if payments for public goods depend on their declared principles (Stiglitz, 1983). Since the contribution of one person is not significant in the total supply of a public good, he will prefer to take a free ride.

(3) The problem of public versus private provision. Most urban services can be provided publicly or privately. The technical definition of the public goods may not be sufficient to exhibit the political character of the related decision (Ranson and Stewart, 1989), and the reason for public provision is traditionally the distributional objectives (Jones et al., 1980). Malkin and Wildavsky (1991) challenge the distinction between public and private goods with the claim that public goods are publicly provided only because of a society's normative judgments on them. Why urban services should be provided publicly remains an important focus of attention in this debate. Whatever the reason for public provision, the problems mentioned above make the decisions on the provision and distribution of public services complicated for public bodies. ${ }^{2}$ However, some factors may explain the distributional patterns for public services (Jones and Kaufman, 1974), such as:

a. the amount of resources available (this affects the overall service level, which may explain the allocation pattern rather than the distribution);

b. the composition and distribution of population, especially the geographical concentration of socio-economic characteristics of users, may explain some of the service distribution patterns; c. the number and intensity of political demands may affect service distribution, particularly to higher income groups; thus, these politically powerful groups are expected to be more effective in affecting the distributional patterns;

d. the needs of citizens must be reflected by the demand to be effective in the distributional patterns; even when the needs of citizens are considered in service distribution, they are mostly defined by its providers.

The incremental character of service allocation and the "distributional uncontrollables" in provision should also be considered. The first involves a distribution pattern which is "more a function of past decisions than present ones" (Jones et al., 1980). Lineberry (1977) points out the contradiction between past allocations and recent consumption patterns. For services that are tied to costly capital developments and land units, distributional patterns can only be changed incrementally. However, empirical research does not always support the possibility of incremental change when the allocation is concerned with expenditure patterns (Kirby, 1985). The level of service expenditure is mostly determined by holistic variables, which include geographical, spatial and locational factors such as the availability of land, the capacity of service providers, and the configuration of income groups in the city (Kirby, 1982; Newton, 1984; Pinch, 1985).

However, municipal bureaucrats tend to interpret the significance of these ecological and spatial factors in such a way that the ultimate allocations are unaffected (Rich, 1979). The rough equality in service distribution-or unpatterned inequality, as it is called by Lineberry (1977) - seems to be the consequence of bureaucratic decisions rather than a product of polit-

\footnotetext{
${ }^{2}$ The allocation problem that refers to a different but related function of the public sector is considered as given. As suggested by Jones (1984), "urban public services are not automatically distributed by the allocation process". A number of factors, including the allocation process, determines the distribution of outputs. Here, it is sufficient to note that even when the allocation is given, the determination of the distributional rule remains unsolved.
} 
ical choice. ${ }^{3}$ Here, equality and equity should be differentiated to separate the output and outcome (or impact) equality; as Rich (1979) states, "services are equally distributed when everyone gets the same service. They are equitably distributed when citizens are in a more nearly equal life circumstance after receiving the services than before." Thus, quality of the services provided and private opportunities for the same service should also be considered in the analysis of public service distribution.

However, the impacts of service allocation vary with citizen characteristics, including socio-economic variables, needs, demands and preferences. In addition to the difficulties in measuring equality of service outcome, received services may be valued differently by varying groups (Walker, 1981). ${ }^{4}$ The question of who these groups are requires a distinction between the territorial justice-geographical distribution through appropriate areas of the city-or distribution with respect to the needs of citizen groups.

\section{Parks and recreational services and supply conditions in Ankara metropolitan city}

\section{Service characteristics}

Parks, like other fixed facilities, cannot be equally accessible to everybody. Thus, it is difficult to provide such services while also considering the characteristics of individuals. This situation leads to territorial justice: the aim to equalize service on a geographical basis (Lineberry, (1977, 1980)).

Prior to the empirical analysis, determining factors in the service's utilization are examined and grouped as service and user factors. The dominant service factors in utilization are distance and accessibility, that can be measured by travel time, congestion level as a measure of comfort, the variety of activities and facilities as a quality indicator, safety, physical attractiveness and maintenance as aesthetic considerations, (Hatry and Dunn, 1971; Massam, 1975). Despite the importance of proximity to a service area, all stated factors should be evaluated together, since these qualities may appear equally dominant for the consumption of recreational services (Forster, 1989).

Obtaining an overall idea of user satisfaction requires the views of non-users as well as active users. As the "citizens are not passive recipients of services" and "can attempt to shape the services", user

\footnotetext{
${ }^{3}$ The dominance of bureaucratic decisions is not independent of service characteristics and central government control (Pinch, 1985), the weaknesses of the studies that have supported the dominance of bureaucratic decision rule in the distribution of urban services, see Miranda and Tunyavong (1994). However, parks and recreational services which are classified as 'common pool resources' by the authors are affected by historical decisions more due to fixed facilities and investments.

${ }^{4}$ Harvey (1973) notes the "overriding values" that widely affect distributional principles such as needs or territorial justice. The social values may accept some services as merit goods, to be equally distributed.
}

characteristics should not be ignored (Rich, 1979; Francis, 1989). Dominant user factors in the utilization of these services can be summarized as neighbourhood characteristics, including density and homogeneity, age, sex, family composition (number of working people and children) and size, income level of the household, education level, car ownership and individual interests.

The hypotheses based upon the above-mentioned factors are tested through the data on household characteristics, service characteristics, and personal preferences and needs. They are discussed together with the analysis and results in Section 4.

\section{Service supply}

In Turkey, parks and recreational services are publicly provided by local government. The reason for public provision is the merit character of this service, which also explains its free supply. ${ }^{5}$ Furthermore, this reputation leads to a consensus on the necessity of equal access to this service. Thus, this service area exhibits all of the distributional problems found in all public goods, and this paper will concentrate specifically on the problem of equal access due to the importance of public provision for low-income groups.

Ankara, capital of the Turkish Republic, had been the stage of planned development since the republic's early period. Today, as a metropolis, it exhibits important features for urban services. Because of the unexpected population increase through migration, early planning efforts ceased and gave way to an uncontrollable development of squatter settlements. This resulted in a combination of declining green areas and increasing land prices, which led the municipality to limit the land used for green areas. As a result, the amount of green areas decreased gradually beginning from the 1960 s, not only in relative size to the city but also in total area (Beler, 1993).

Local government structure has consisted of a twotier system for Turkish metropolises since 1984. Both metropolitan and district municipalities claim responsibility for the provision of urban public services, including parks and recreational services. However, the division of responsibility that is based only on the service scale does not help to solve the distributional problems. Parks larger than $30000 \mathrm{~m}^{2}$ have

\footnotetext{
${ }^{5}$ Theoretically, this service is not a pure public good, as congestion affects its utilization. As stated by Bourassa (1992), "An attractive public park is not a pure public good because it may become so crowded that its enjoyment is impaired." Technically, scale economies exist in the provision of the service, which make private provision possible. However, congestion parameters may be different depending on the local service conditions and population characteristics. Forster (1989) notes the need for a specific survey on congestion levels in different recreational sites. The results would be more interesting for countries like the USA, which has more exclusive recreational services (see Christopherson (1994) for the recent trends of exclusion from urban services). Turkey is still in the stage of public provision mainly because of the traditional merit character of this service.
} 
been provided and maintained by the metropolitan municipality, whereas for all of the smaller neighbourhood parks, district municipalities claimed responsibility. This structural change complicated the problem of distribution because it added bureaucratic bottlenecks to the decision process, like increasing private influence and the need for further coordination. Jones (1984) claims that this fragmented system may result in less service for the poor and more corporate influence in local decision-making than would be the case in a more centralized system. Parks and recreational services are open to this influence, as available land is a very relevant constraint. Figure $I$ illustrates the existing allocation of park and recreational services in Ankara.

As can be seen, the amount of overall supply is very limited despite the small differences among districts. This being the case, larger parks appear to be an important part of the service provision. Additionally, this study is not affected by changes in supply conditions or allocation patterns, as the distributional rule has always been the same. This rule seems rather close to territorial justice, by which an equal distribution of the service is maintained regardless of its impacts. An equal amount of park area is aimed for each district without considering the population and service characteristics. The incremental character of service provision also prevents a radical shift in the allocation, as the park distribution in Ankara indicates. When the problem of distribution is applied there, it appears that differences among jurisdictions (which also create differences in their need for services) are effective in the utilization of parks and recreational services. The results of an empirical survey to study the utilization of park services in Ankara is evaluated in the following section.

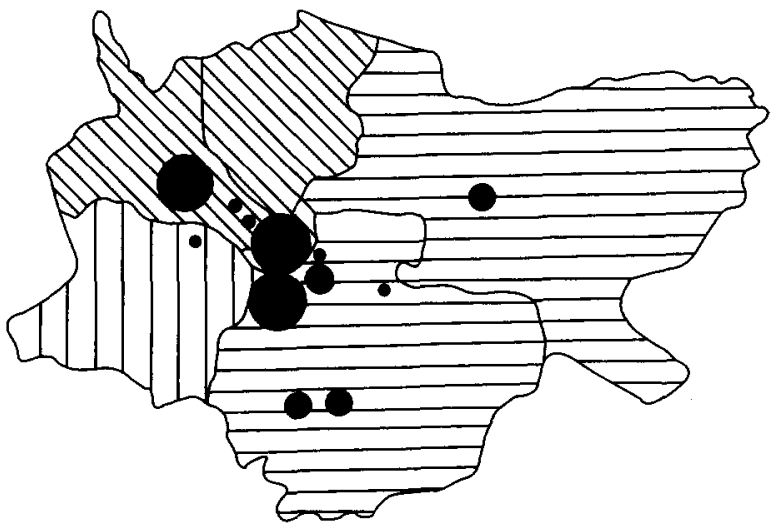

Figure 1 Allocation of parks and recreational services in Ankara.

Key: District parks (per capita $\mathrm{m}^{2}$ ): $0.30-0.40$, 0.41 0.60 , 目 0.61-0.80. Larger parks $\left(\mathrm{m}^{2}\right)$ : $\bullet 30000-60000$, $61000-120000$, $250000+$.

\section{Analysis and results}

In this survey, the impacts of the spatial distribution of parks and recreational services are evaluated through hypotheses based upon the above-mentioned service and user factors. The basic hypotheses are summarized below.

(1) Demographic characteristics of householdshousehold size, age groups, and number of working people-are expected to affect the utilization of the nearest park.

(2) Socio-economic characteristics such as income level and home and car ownership may have an influence on park utilization in general. Increasing income and car ownership, which indicate higher mobility, may increase the possibility of using other private facilities, whereas home ownership may lead to a higher involvement in the neighbourhood parks.

(3) The utilization of the nearest park is expected to increase with proximity.

(4) Quality may be an important factor to determine park utilization and satisfaction. The effect of distance is expected to decrease with increasing quality of the park.

In addition to these hypotheses, people are asked their purpose for use, reasons for dissatisfaction, and reasons for not using the nearest park as well as other parks and private alternatives. Due to the importance of externalities of larger parks with extended facilities, the externalities are separately analyzed with questions on user frequency, duration and purpose of use, travel mode of users, cost of using, and perceptions about other users. As the claim of the municipality is to serve all citizens with larger parks, the locality of the users also seems important.

A questionnaire covering household and service characteristics, as well as the preferences and needs of citizens, was applied to a distance-based sample. ${ }^{6}$ The distance to the nearest park was considered as a basis for the selection of sample citizens for the empirical survey. General characteristics of the households in the sample can be seen in Table 1 .

Before stating the results, some adjustments that were performed to increase the reliability of data should be mentioned.

\footnotetext{
${ }^{6}$ Quota sampling was chosen as the appropriate method in order to compare citizen groups with respect to the allocated service level. Having an equal number of responses from each distance category, the total area of parks in each division is divided to the population density of that division. These indices are grouped to represent each distance category. In this selection, socio-economic characteristics of the population are also considered, so that all income levels are covered in the sample. Responses are then collected by a random selection of streets and dwellings in the divisions to be surveyed. The sampling from the houses allows the survey to cover the responses of non-users as well as the users, as required by a study on park utilization and satisfaction. In this way, a total of 223 people are covered in the sample.
} 
Table 1 General characteristics of the households in the sample

\begin{tabular}{|c|c|c|c|c|c|c|c|c|c|c|}
\hline Household size & 1 & 2 & 3 & 4 & 5 & 6 & 7 & 8 & 9 & $10+$ \\
\hline No. of observations & 7 & 36 & 58 & 53 & 32 & 13 & 6 & 10 & 3 & 5 \\
\hline$\%$ of observations & 3.14 & 16.14 & 26.00 & 23.77 & 14.35 & 5.83 & 2.69 & 4.48 & 1.35 & 2.24 \\
\hline No. of working people & 0 & 1 & 2 & 3 & 4 & 5 & & & & \\
\hline No. of observations & 34 & 106 & 64 & 15 & 3 & 1 & & & & \\
\hline$\%$ of observations & 15.24 & 47.53 & 28.69 & 6.72 & 1.34 & 0.48 & & & & \\
\hline No. of children & 0 & 1 & 2 & 3 & 4 & 5 & 6 & 7 & 8 & \\
\hline No. of observations & 107 & 58 & 34 & 13 & 4 & 3 & 2 & 1 & 1 & \\
\hline$\%$ of observations & 47.98 & 26.00 & 15.25 & 5.83 & 1.79 & 1.35 & 0.90 & 0.45 & 0.45 & \\
\hline Adjusted income level & 1 & 2 & 3 & 4 & Unknown & & & & & \\
\hline No. of observations & 53 & 59 & 67 & 39 & 5 & & & & & \\
\hline$\%$ of observations & 23.77 & 26.46 & 30.04 & 17.49 & 2.24 & & & & & \\
\hline Home-owners & 128 & $57.40 \%$ & & & & & & & & \\
\hline Non-home-owners & 95 & $42.60 \%$ & & & & & & & & \\
\hline Car-owners & 100 & $44.84 \%$ & & & & & & & & \\
\hline Non-car-owners & 123 & $55.16 \%$ & & & & & & & & \\
\hline
\end{tabular}

(1) To prevent collinearity due to the dependency on home and car ownership, an adjusted income is calculated that combines home and car ownership. In this calculation, each income level is extended to cover home and/or car ownership in such a way that the stated levels shift upward in the case of home and/or car ownership. When a household owns a house and/or car, its income level rises one level, as home either/or car ownership require a high income.

(2) Park distance categories, which are measured by the walking time, are grouped under four categories: less than 5 minutes, 5-15 minutes, more than 15 minutes and unknown.

(3) Household size is grouped under three categories (1-2 people, 3-5 people, or more than five people) to obtain sufficient observations representing different family types from nucleus to extended.

(4) The number of working people in the household is analyzed as a ratio of working people to total household size, in order to obtain clues for potential leisure time and users per household.

For the statistical analysis, cross-tabulation is utilized to calculate $\chi^{2}$ values indicating the relationship between two variables selected according to the hypotheses. All statistical tests are carried out at a 95\% confidence level. The results can be seen in Table 2.

Hypotheses that are verified by the statistical analysis are given below.

(1) Income level is not statistically independent of the utilization of the nearest park $\left(\chi^{2} 8.82\right)$. This relationship indicates a higher rate of utilization as income increases. This is probably because of the lack of a nearby park in the low-income neighbourhoods. Another reason might be the higher ownership of private gardens among those in the lowest income level. ${ }^{7}$

${ }^{7}$ Income and having a private garden appear to be statistically dependent in the analysis $\left(\chi^{2} 12.02\right)$. However, $33 \%$ of the subjects
(2) Distance and park utilization are significantly dependent upon one another, with the lowest utilization for the maximum distance category $\left(\chi^{2}\right.$ 26.75).

(3) Car ownership and utilization of other alternatives are also statistically dependent $\left(\chi^{2} 36.10\right)$. Larger urban parks, picnic areas inside and outside the city, and private clubs and gardens are stated among the alternatives.

Other hypotheses on the relation between sociodemographic characteristics and park utilization such as household size, age groups, number of children, and number of working people and park utilization are not verified by the sample data. This may be a consequence of quota sampling, in which biases may emerge (for example, the number of children per surveyed household is lower than the city average, with families with one child or no children constituting $74 \%$ of all surveyed households), as well as the dominance of ecological factors for this service, as stated by Newton (1984). To test the role of awareness in utilization, the users are also asked if they know the name of the nearest park. However, utilization did not appear dependent on knowing the name of the park, which may indicate that the users are informed about the park.

The use of private possibilities appears to be dependent on income level and car ownership either as composite or separate variables. Recreational choices that require a higher mobility are used increasingly by the upper-income levels. Furthermore, picnic areas outside the city are stated, $37 \%$ mostly by upper-income level, who have the highest mobility. However, the most frequently stated recreational choice is the private garden $(42.6 \%)$, and it is the choice of lowerincome groups, whereas the second most important

using a private garden as a recreational choice come from the lowest income level, as opposed to only $9 \%$ from the highest. This stems from the local settlement characteristics of low-income groups which are dominated by squatters with gardens. 
Table 2 Results of the statistical analysis

\begin{tabular}{lll}
\hline Variables tested against park utilization & Relationship & Comments \\
\hline Household size & No & Dominance of ecological factors \\
Age groups & No & Dominance of ecological factors \\
Number and age of children & No & Sample bias \\
Number of working people & No & \\
Home ownership & No & Lack of supply \\
Income level & Yes & Having a private garden in low-income dwellings \\
Distance & Yes & Lack of sufficient supply \\
Aesthetic quality & No & Higher mobility \\
Car ownership-other alternatives & Yes & Public character of parks \\
Income level-utilization of larger parks & No & Increasing impact of social values on park \\
Perception of other users-utilization of larger parks & Yes & utilization \\
\hline
\end{tabular}

anless otherwise stated, utilization of the nearest park is mentioned.

Table 3 Utilization rates of lager parks

\begin{tabular}{llllll}
\hline Parks & Year of construction & Size $\left(\mathbf{m}^{\mathbf{2}}\right)$ & Users/district sample $^{\mathbf{a}}$ & District users/all users $^{\mathbf{b}}$ & All users/all sample $^{\mathbf{c}}$ \\
\hline 1 & 1935 & 260000 & 0.40 & 0.13 & 0.28 \\
2 & 1957 & 32800 & 0 & 0 & 0 \\
3 & 1965 & 11000 & 0.14 & 0.55 & 0.14 \\
4 & 1971 & 72300 & 0.17 & 0.63 & 0.14 \\
5 & 1981 & 37000 & 0.04 & 0.29 & 0.08 \\
6 & 1983 & 65000 & 0.26 & 0.67 & 0.21 \\
7 & 1984 & 30000 & 0.03 & 0 & 0.02 \\
8 & 1985 & 250000 & 0 & 0.18 & 0.05 \\
9 & 1986 & 56000 & 0.06 & 0 & 0 \\
10 & 1988 & 35000 & 0 & 0 & 0 \\
11 & 1991 & 43000 & 0 & 0 & 0 \\
12 & 1991 & 630000 & 0.25 & 0.36 & 0.06 \\
13 & 1994 & & & & \\
\hline
\end{tabular}

${ }^{a}$ The ratio of park users to the subjects living in the same district as the park.

'The ratio of park users living in the same district as the park to the total number of users of the park.

cThe ratio of all users of the park to the total number of subjects.

choice, the use of balconies (40\%), is stated by all income groups.

The utilization of larger parks that are planned to serve all citizens is evaluated separately to illustrate the role of park quality. ${ }^{8}$ Park utilization is still expected to be dependent on distance, but is probably not as effective in the case of neighbourhood parks. The rates of utilization for these parks by the population of various districts surveyed can be seen in Table 3.

Since the number of subjects from each district is considerably different, ratios are utilized instead of the number of users. The ratio of all park users to the total number of subjects also tests the claim of municipalities, viz., that parks are used by all citizens. When the responses are evaluated, proximity appears to be important for the utilization of larger parks as

\footnotetext{
${ }^{8}$ These parks vary in size from 30000 to $640000 \mathrm{~m}^{2}$, as well as in the type of activities and facilities provided. Duration of use and transportation costs required to reach the park, which may be important for the low-income groups, are asked. Additionally, purpose of use and perceptions of other users are questioned.
}

well. However, some parks are used by all citizens to varying degrees with a proximity concern, whereas others are never used even by the district population. It seems that the age and size of the parks are not dominant issues in the decisions of citizens whether to use or not use a park. This may indicate a quality concern for larger parks, as user expectation is higher due to their size and range of activities, as well as the time and money spent for their use. Surprisingly, their utilization is not found statistically dependent on income level and car ownership. The only significant relation appears between the perception of other users and utilization $\left(\chi^{2} 9.66\right)$. Rate of utilization increases with a positive perception of other users, whereas a negative one discourages people from using them. ${ }^{9}$

\footnotetext{
${ }^{9}$ Their opinions about other users are evaluated with respect to the content and style of the responses. Negative and positive value judgments are detected through wording and explanations about their feelings toward other users. This tendency toward homogenization may constitute a basis for privatization of public spaces in Turkey, as in the case of many US examples (Zukin, 1991; Mitchell, 1995).
} 
When use of the nearest park is concerned, only $35.4 \%$ state themselves as users, whereas $64.6 \%$ are non-users. The frequency of stated usage objectives such as refreshment and resting, which are stated by $56 \%$ of users, and viewing landscape and greenery $(31 \%)$ indicate a high involvement in passive outdoor recreation. Taking the children and using sport facilities, each are stated by $30 \%$ of users. Other objectives-entertainment $(11 \%)$, gathering with friends $(11 \%)$, and leisure $(13 \%)$ - -are stated with similar low frequencies. Usage objectives are also tested against income levels to understand the differences among them.

As a result, children and sports are more frequently stated in the lowest income level. This may point out a need for more basic facilities among low-income groups. Although these are slight indicators with a limited number of observations, they may support the claim that supply conditions affect the structure of demand.

Among the reasons for dissatisfaction, lack of facilities is the most important complaint and is stated by $50 \%$ of dissatisfied users, while congestion and noise are stated by $49 \%$. They are followed by the services offered, which $40 \%$ complained about. Despite the quality concerns of dissatisfied users, it should be noted here that they are only 42 people out of the whole sample. However, this is $53 \%$ of the user group.

The reasons for not using the nearest park were asked of 144 non-users. Distance is stated by $43.8 \%$ as the first reason, which may support the importance of proximity in park utilization. Limited leisure time follows with $27 \%$, while dislike for other users $(14.5 \%)$, dislike for the park $(13.8 \%)$, and not having the need for this service $(12.5 \%)$ are the other reasons stated. Financial limitations appear to be of negligible importance, since only three people $(2 \%)$ mention it. This is because of the public character of neighbourhood parks in Turkey. ${ }^{10}$

When the above reasons are examined with respect to income levels, leisure is less frequently stated by lower-income groups than higher ones. As expected, distance is stated by the lowest income group more frequently. The percentage of people who dislike the park or its other users is saliently higher in the highest income group, despite the insufficiency of observations to conclude a statistically significant difference between income levels. However, it may indicate that people with higher income and status are more concerned with taste, probably because they have the possibility of higher satisfaction of the need for park services through private alternatives.

\footnotetext{
${ }^{10}$ For a comparison on the importance of constraints to park use, see Scott and Jackson (1996).
}

\section{Discussions and conclusion}

The utilization of the nearest park and other recreational facilities in Ankara is mainly determined by the user's income level and distance from the service area. Here, the peculiar relation between income and use should be noted. This may be either because of the lack of nearby parks in lower-income neighbourhoods, the possibility of having a private garden, or both. Squatters with private gardens provide the lower income groups with this possibility. However, this group's complaints about the lack of a neighbourhood park, and the utilization of the larger parks by this income group, indicate their need for this service. These complaints cannot create an active demand from people living in the low-income areas (see Mitchell (1995) for a discussion on active participation on the use of public spaces). After reviewing various pieces of empirical research, Burnett (1984) concludes that "political demands are not the only, or even the most important criteria in the allocation of urban public resources or service provision." In Turkey, there is not a strong tradition of local political action on the use of public spaces, as seen in the case of Ankara. Besides, as demand is a function of supply, it is expected that an increase in supply will stimulate the demand.

Another important result is the low level of involvement in quality concerns except for the negative perception of other users. This result verifies claims that people often decide to use a park on the basis of other users, rather than for the landscape features or recreational opportunities (Hayward, 1989). Surprisingly, demographic characteristics and leisure time are not among the determining factors in service utilization. The number and age of children are expected to be strongly related to the use of the nearest park. However, it can be observed that taking the children to the nearest park is more common with lower-income groups in explaining their usage objective.

Further policies in this service area should consider income levels of neighbourhoods and the importance of the distance to target users, as proximity appears more important for the low-income groups with less mobility. For these groups, park usage might be promoted by establishing neighbourhood parks. Quality considerations seem to be postponed due to the lack of adequate service in quantitative terms. This is verified by the fact that low-income groups are more concerned with park facilities and security, whereas the higher-income groups are more concerned with maintenance, followed by facilities. Higher-income groups state congestion as a problem more frequently, indicating that this service is more public for the lowincome groups. Furthermore, satisfaction level from the nearest park is rather high in the highest income level. Since usage objectives differ for various income levels, relevant service should be provided instead of a standardization of service output throughout the 
city. ${ }^{11}$ Sports facilities and playgrounds for children are needed more in low-income neighbourhoods, whereas landscape and greenery are desired more by high-income groups. Thus, small-scale, single-purpose facilities with regular maintenance may solve most of the problems of all income levels. Even district municipalities with limited finances and land availability can afford such investments.

The results also indicate that larger parks owned by metropolitan municipalities and planned for the whole city are used by those from varying distances, but with more concern for the quality travel time and higher expectations from users. Data show that users will travel more for better service or quality. Thus, investment should be directed to regularly maintained larger parks with a wide range of facilities and services, without much concern for their location in the city. The existence of parks that are not used even by their district's population supports this claim. Citizens' preference for the larger parks are based upon their facilities and the services provided.

In spite of the fact that inequality in the distribution of parks and recreational services in Ankara does not appear to be intentional, it tends to favour highincome neighbourhoods due to historical, spatial and locational variables. The case of this service area seems to reflect "continuing cumulative inequality in broader aspects of social, economic and environmental deprivation" (Pinch, 1985). The process is rather close to 'voting with the feet', by which citizens receive better services by means of their locational choice. Cox (1984) calls this process the "commodification" of neighbourhood, in which better services serve as a common denominator in the "homogenisation of preferences'. This being the case, local service expenditure tends to concentrate in clusters formed by high-income groups. It can be concluded that there is no evidence which would support the underclass hypothesis for the distribution of parks and recreational services in Ankara. Rather, it seems that ecological and bureaucratic factors affect the distribution together. The overall shortform of this service should be considered in order to comprehend the importance of access to the limited service areas. In this respect, local policies are extremely important despite limitations in the decision-making process.

As a result, the policy should aim at achieving distributional justice, targeting the satisfaction of different user groups, rather than a territorial justice, which is the current policy of the municipality for this service. Further studies on the needs and preferences of the users and current non-users are necessary to programme park services appropriately and increase willingness to use public parks (Scott and Jackson, 1996).

\footnotetext{
"Neighbourhood parks that fit the cultural patterns of the neighbourhood are the ones that are most likely to be used, as stated by Marcus et al (1990). Unfortunately, this is a further issue which is ignored in the distribution of parks in Ankara due to limitations in supply.
}

However, this study points out the need for effective strategies in the distribution of parks and recreational services, even if the overall service is limited. Neighbourhood parks with limited or single facilities are required by low-income groups, whereas the larger parks are used by all income levels. The utilization of larger parks can be increased by a higher quality. Low-income groups might be supported by policies that provide cheaper or free transport services from the neighbourhood to larger parks. ${ }^{12}$ These are a few suggestions to increase the utilization of the service and satisfaction of the users. More can be added as long as the providers appreciate the importance of the equitable distribution of urban services.

\section{References}

Beler, F (1993) The distributional impacts of urban public services: parks and recreational services in Ankara, unpublished $\mathrm{PhD}$ thesis, METU, Department of City and Regional Planning, Ankara.

Bourassa, S C (1992) 'Public welfare and the economics of landscape aesthetics'. Landscape and Urban Planning 22, 31-39.

Burnett, A (1984) 'Neighborhood participation, political demand making and local outputs in British and North American cities', In Kirby, A, Knox, P and Pinch, S (eds) Public Service Provision and Urban Development, pp 316-362, Croom Helm, London.

Christopherson, S (1994) 'The fortress city: privatized spaces, consumer citizenship', In Amin, A. (ed.) Post-Fordism: A Reader, pp 409-427, Basil Blackwell, Oxford.

Coalter, F (1990) 'Analysing leisure policy', In Henry, I P (ed.) Management and Planning in the Leisure Industries, pp 149 178, Macmillan, London.

Cox, K R (1984) 'Social change, turf politics and concepts of turf politics', In Kirby, A, Knox, P and Pinch, S (eds) Public Service Provision and Urban Development, pp 283-315, Croom Helm, London.

Forster, B A (1989) 'Valuing outdoor recreational activity: a methodological survey'. Journal of Leisure Research 21 $181-201$.

Francis, M (1989) 'Control as a dimension of public space quality', In Altman, I and Zube, E $\mathrm{H}$ (eds) Human Behavior and Environment: Advances in Theory and Research, Plenum Press, New York

Goldin, K D (1977) 'Equal access vs. selective access: a critique of public goods theory'. Public Choice 29, 53-71.

Harvey, D (1973) Social Justice and the City, Edward Arnold, London.

Hatry, H P and Dunn, D R (1971) Measuring the Effectiveness of Local Government Services, Recreation, The Urban Institute, Washington, DC.

Hayward, J (1989) 'Urban parks: research, planning and social change', In Altman, I and Zube, E H (eds) Human Behavior and Environment: Advances in Theory and Research, Plenum Press, New York.

Jones, B D (1984) 'Political decision-making and the distribution of public benefits, a political science perspective', In Kirby, A Knox, P and Pinch, S (eds) Public Service Provision and Urban Development, pp 363-389, Croom Helm, London.

\footnotetext{
${ }^{12}$ The definition of quality should consider the problem of social diversity, which can be handled by appropriate design solutions as well by social policies in a more general context. The political debates over the supply of parks and recreational services are not considered intentionally, as the Turkish case does not reflect any conscious choice other than public and free provision of this service. (For a good summary of the related political perspectives see Coalter, 1990.)
} 
Jones, B. D. and Kaufman, C. (1974) 'The distribution of urban public services'. Administration and Society 6, 337-360.

Jones, B D, Greenberg, S R, Kaufman, C and Drew, J (1980) 'Service delivery rules and the distribution of local government services', In Hahn, H and Levine, C (eds) Urban Politics, pp 225 249, Longman, New York.

Kirby, A (1982) The Politics of Location, Methuen, London and New York.

Kirby, A (1985) 'Leisure as commodity: the role of the state in leisure provision'. Progress in Human Geography 9, 64-84.

Lineberry, R L (1977) Equality and Urban Policy, The Distribution of Municipal Public Service, Sage, Beverly Hills, CA.

Lineberry, R L (1980) 'Mandating urban equality', In Hahn, $H$ and Levine, C (eds) Urban Politics, pp 173-200. Longman, New York.

Lineberry, R L and Welch, R E (1974) 'Who gets what: measuring the distribution of urban public services'. Social Science Quarterly 54, 700-712.

Malkin, J and Wildavsky, A (1991) 'Why the traditional distinction between public and private goods should be abandoned'. Journal of Theoretical Politics 3, 355-378.

Marcus, C C, Watsky, C M, Insley, E and Francis, C (1990) 'Neighborhood parks', In Marcus, C C and Francis, C (eds) People Places: Design Guidelines for Urban Open Space, Van Nostrand Reinhold, New York.

Massam, B (1975) Location and Space in Social Administration, Halsted, New York.

Mayer, M (1994) 'Post-Fordist city politics', In Amin, A (ed.) PostFordism: A Reader, pp 316-337, Basil Blackwell, Oxford.

Miranda, R A and Tunyavong, I (1994) 'Patterned inequality? reex- amining the role of distributive politics in urban service delivery'. Urban Affairs Quarterly 29, 509-534.

Mitchell, D (1995) 'The end of public space? People's park, definitions of the public, and democracy'. Annals of the Association of American Geographers 85, 108-133.

Newton, K (1984) 'Public services in cities and countries', In Kirby, A, Knox, P and Pinch, S (eds) Public Service Provision and Urban Development, pp 19-43, Croom Helm, London.

Pinch, S (1985) Cities and Services, Routledge \& Kegan Paul, London.

Ranson, S and Stewart, J (1989) 'Citizenship and government: the challenge for management in the public domain'. Political Studies 37, 5-25.

Rich, R C (1979) 'Neglected issues in the study of urban service distribution: a research agenda'. Urban Studies 16, 143-156.

Scott, D and Jackson, E L (1996) 'Factors that limit and strategies that might encourage people's use of public parks'. Journal of Park and Recreation Administration 14, 1-17.

Stiglitz, J E (1983) 'Twenty-five years after Tiebout: a perspective', In Zodrow, G R (ed.) Local Provision of Public Services: The Tiebout Model after Twenty-five Years, pp 17-53, Academic Press, New York.

Toulmin, L M (1988) 'Equity as a decision rule in determining the distribution of urban public services'. Urban Affairs Quarterly 23, 389-413.

Walker, B (1981) Welfare Economics and Urban Problems, Hutchinson, London.

Zukin, S (1991) Landscapes of Power: From Detroit to Disney World. University of California Press, Berkeley and Los Angeles, CA. 